\title{
Alienação parental e judicialização das relações familiares
}

\author{
Parental alienation and judicialization of family relations
}

Débora Augusto Franco

Instituto Fderal de Educação, Ciência e Tecnologia do Rio de Janeiro

\section{RESUMO:}

O presente artigo constitui uma das linhas de análise de um projeto de pesquisa desenvolvido junto ao Instituto Federal do Rio de Janeiro (IFRJ) como desdobramento de um trabalho de doutoramento em Psicologia. Trata-se de colocar em debate a produção social da chamada "Síndrome da Alienação Parental" (SAP). Participaram da pesquisa 12 sujeitos, 10 homens e 2 mulheres que romperam o laço conjugal há, no mínimo, 1 ano e, no máximo, 10 anos, e que fazem parte de comunidades virtuais que abordam o tema alienação parental na rede social conhecida como Facebook. Tendo como inspiração a perspectiva foucaultiana, questionam-se as estratégias judicializantes que, atreladas às relações de poder, dispersam a compreensão sobre o contexto em que se deflagra a suposta síndrome. Como resultado, foi observado que o litígio se mascara nas narrativas de vivência da alienação parental e no discurso denuncista que convoca a necessidade de criminalização.

Palavras-chave: alienação parental; judicialização; litígio.

\section{ABSTRACT:}

The present article constitutes one of the lines of analysis from a research project elaborated with the Instituto Federal do Rio de Janeiro (IFRJ) as a division of a doctoral work in psychology. The study aims to raise the debate about the social production of the called "parental alienation syndrome". 12 subjects participated in the survey - 10 men and 2 women - who have broken the conjugal bond for, at least, one year and, at most, ten years, and participate in virtual communities that treat about the theme of parental alienation in the social media known as Facebook. Having Michel Foucault's work as an inspiration, the judicializing strategies that, tied to power relationships, disperse the comprehension about the context in which emerges the supposed syndrome are questioned. As a result, it was observed that the litigation hides itself in the narratives of the parental alienation experiencing and in the denouncing discourse which summons the necessity of criminalization.

Key-words: parental alienation; criminalization; litigation. 


\section{Introdução}

O presente artigo é resultado de uma das linhas de análise de um projeto de pesquisa desenvolvido junto ao Instituto Federal de Educação, Ciência e Tecnologia do Rio de Janeiro (IFRJ) como desdobramento de um trabalho de doutoramento em Psicologia pela Pontifícia Universidade Católica do Rio de Janeiro (PUC-Rio), em que foi utilizada a metodologia da análise de conteúdo. No presente artigo, retomamos os dados coletados durante o percurso de doutoramento para nos permitir um outro olhar sobre a pesquisa e o pesquisar. Aqui, pretendese colocar em debate a produção social de uma ideia de Síndrome da Alienação Parental (SAP) e de criminalização da alienação parental que, calcada no modelo patologizante, produz modos de ser, pensar, agir e sentir as vivências de litígio no meio intrafamiliar. Neste sentido, temos como objetivo investigar os processos sociais de judicialização e criminalização da família pós divórcio na narrativa dos pais que relatam ter vivenciado a alienação parental. Nesse cenário, utilizamo-nos da inspiração na perspectiva foucaultiana para pensar as estratégias jurídicoestatais de intervenção junto às famílias em litígio como atreladas às relações de poder relações de força imanentes materializadas em práticas, técnicas e disciplinas presentes em todo o corpo social de forma dispersa e inapreensível materialmente. A partir daí, parte-se para repensar a relação entre Estado e políticas públicas de orientação às famílias pós-divórcio que, supostamente, vivenciam a chamada alienação parental.

Na prática profissional como psicóloga no âmbito da justiça, mais especificamente como assistente técnica, notou-se que no diagrama que engendra vidas criminalizadas no território das Varas de Família, o dispositivo de produção de subjetividade envolve as mais variadas facetas, sendo o Estado e suas políticas públicas ou ainda, a ausência destas, uma parte constituinte de uma malha de processos sociais, políticos, econômicos e socioafetivos. Com isso, torna-se equívoco pensar uma suposta separação entre o plano político e o plano subjetivo, devendo-se considerar que essas duas dimensões estão em constante relação. Pensar justiça no âmbito da família implica reconhecer que políticas governamentais (leis, regulamentos, intervenções médico-psicológicas e/ou sociais) não se restringem a instituições estatais, mas se atualizam no campo social, compondo a própria subjetividade. Com efeito, pode-se afirmar que as estratégias de poder presentes nos mecanismos de segurança e justiça e atualizadas no 
acompanhamento das famílias em litígio se coadunam com determinadas práticas de especialistas, que têm como objetivo encerrar a responsabilidade por uma situação complexa e adversa, individualizando a suposta vivência de alienação parental, que, por sua vez, é entendida como um processo particular e intencional, promovido por um dos genitores e/ou seus pares, com o objetivo de manipular o (s) filho (s) para se afastar e odiar o outro genitor, tal como proposto por Gardner $(1991 ; 2002)$.

Nos dirigimos ao conceito de Síndrome da Alienação Parental (SAP) como uma conjectura, tendo como base a própria literatura específica, que aponta para a existência de discordâncias sobre a caracterização da então suposta alienação parental. Há desacordos em relação à nomenclatura específica com base no que caracteriza a alienação parental: uma síndrome ou um fenômeno sociofamiliar. Destaca-se que a interpretação diagnóstica da SAP encontra-se amparada na ideia de patologia psiquiátrica (BOLAÑOS, 2005; FERMANN et al, 2017; GARDNER, 1991; 2002; GONZALEZ, CABARGA; VALVERDE, 1994; NUSKE; GRIGORIEFF, 2015; SOUSA; BRITO, 2011; WALLERSTEIN; KELLY, 1998). Neste estudo destaca-se que caberia pensá-la a partir das relações de poder marcadas pelo complexo social, jurídico e familiar e pela dinâmica conflitual, característicos da lide, que implicaria em colocar os filhos no centro da disputa. Nesta pesquisa, considera-se, então, o que foi destacado por alguns autores (SOUSA, 2010; SOUZA, BRITO, 2011), a partir da ideia de que a síndrome não foi reconhecida pela comunidade médica e, por isso, a alienação parental deve ser entendida como um fenômeno sociofamiliar - e não a uma patologia - e está associada às dificuldades do ex-casal em superar os conflitos relativos à separação conjugal litigiosa.

Caracterizar a alienação parental como uma síndrome seria uma forma de patologizar, ou seja, de compreender comportamentos e dificuldades relacionados à esfera familiar como uma doença, uma síndrome ou um transtorno psiquiátrico. Pensar a alienação parental como uma patologia implica favorecer o predomínio da lógica medicalizante, imposta às famílias em situação de litígio, na qual o (s) doente (s), do ponto de vista sintomatológico, são os filhos e também um de seus genitores. A medicalização caracteriza-se pela apropriação médica ou farmacológica dos modos de vida humanos, individualizando características de expressão da existência e as categorizando como uma expressão patológica (ZORZANELLI; ORTEGA; BEZERRA JUNIOR, 2014). Com isso, o processo de medicalização interfere na construção de regras, normas, valores e costumes de ordem sexual, alimentar, familiar, educacional, higiênico e etc, determinando a variação permitida de comportamentos prescritos como 
adequados ao campo social (FOUCAULT, 1979). Nesse processo, há ainda a culpabilização: com amparo na individualização do problema de ordem social, cultural e política, direciona-se a um indivíduo a responsabilidade - neste caso, ao suposto genitor alienador, tal como proposto por Gardner (1991). Gardner (1991) identificou como genitor alienante eminentemente a mãe, vista como culpada pelo desenvolvimento da síndrome na vida de crianças e adolescentes. Nesse sentido, destaca-se a omissão dos fatores sociais, culturais e históricos que, a partir de lógicas normativas sobre as famílias, produziu modelos de cuidado e provisão para progenitoras e progenitores, respectivamente (DONZELOT, 1980). Com a patologização/medicalização, pouca ou nenhuma responsabilização do Estado na manutenção de lógicas individualizantes é pensada. A individualização e a culpabilização de mães produzem o incremento da noção de indivíduo (SILVA, 2005) e, com isso, a responsabilidade exclusiva e unilateral de mulheres. As famílias, marcadas por rótulos que discriminam bons e maus genitores, viram sintomas, desequilíbrios e disfuncionalidades. A partir da conceituação de GARDNER (1991) acerca das características da SAP, acredita-se que, com o comportamento alienante de um dos genitores, os filhos apresentem sinais e sintomas patológicos e, para isso, criam-se técnicas de intervenção médica, psicológica e estatal não apenas sobre as crianças e os adolescentes, mas também sobre suas famílias.

Canguilhem (2002), quando discute o estado patológico a partir da concepção de saúde e doença, afirma que a normalização é uma estratégia de "imposição de uma exigência a uma existência" (p. 211). Em outras palavras, o retorno a um estado de normalidade é pautado em uma norma ou regra forjada no campo social. As normas, que funcionam como um ponto de referência, servem à correção de algo fora do padrão ou modelo dito normal. O normal, por sua vez, seria uma extensão e exibição da norma, que multiplica regras e as indica. Nesse sentido, institucionalizam-se estratégias de controle a tudo que escapa às normas. Nada deve existir fora delas, nada deve fugir às suas exigências, o que inclui a adequação das famílias às lógicas de padronização.

Em alinhamento conceitual com a ideia de SAP, Bolaños (2005), em pesquisa realizada na Espanha, destaca que há uma dimensão patológica, e não cultural, dos conflitos familiares que atinge a relação parento-filial. Diferente de Gardner, para Bolaños (2005), a SAP é uma síndrome familiar e não individual, e que se manifesta em sintomas presentes em todos os membros da família, o que o faz divergir, inclusive, da caracterização nosológica para os transtornos psiquiátricos. De toda maneira, trata-se de uma visão patologizante da alienação 
parental. Já para Wallerstein e Kelly (1998), não cabe pensar a alienação parental como uma patologia, já que haveria, na verdade, o que as autoras definem como alinhamento. $O$ alinhamento a um dos pais é característico da relação estabelecida entre a (s) criança (s) e os pais, especialmente nas condições de divórcio litigioso, quando as crianças encontram-se mais vulneráveis e podem ser levadas pela emoção de um dos genitores, que consegue envolver os filhos em sentimentos como raiva e rancor em relação ao outro genitor. Para as autoras, portanto, não caberia pensar a alienação parental como uma patologia, mas é importante considerar que a criança pode construir uma intensa identificação com um dos pais, o alinhamento, e que, nesse processo, um dos genitores e o (s) filho (s) se unem em um potente ataque contra o outro progenitor, o que deve ser entendido, no entanto, como um fenômeno característico da lide após a separação conjugal (WALLERSTEIN E KELLY, 1998)

A despeito dos impasses em torno do fenômeno da alienação parental, sua caracterização, identificação e intervenção, a Lei de $n^{\circ}$ 12.318/2010 (BRASIL, 2010) intenciona evitar o comportamento alienante do genitor e, assim, o desenvolvimento da hostilidade do (s) filho (s) para com um de seus pais. Com o objetivo de evitar alianças entre pais e filhos que excluam um dos genitores da relação familiar, ou ainda, de impedir a alienação parental promovida pelo genitor alienante, esteve em análise na Câmara de Deputados Federais o Projeto de Lei - PL 4488/2016 (BRASIL, 2016), arquivado em junho de 2018, que pretendia criminalizar a alienação parental. O Projeto de Lei 4488/2016 (BRASIL, 2016) pretendia tornar crime a conduta alienante, com previsão de pena de detenção de 3 meses a 3 anos, em regime aberto ou semiaberto. Havia ainda a possibilidade do regime fechado, que deveria ser determinado pela justiça em caso de reincidência do comportamento alienante. Destaca-se que este é um dos temas mais presentes nas comunidades virtuais pesquisadas, a criminalização da alienação parental, que levanta o debate entre os seus interlocutores, que expressam suas opiniões acerca da criminalização.

Tomando como fio condutor a questão da criminalização na atualidade, pretende-se localizar o tema da judicialização das relações familiares num contexto social, político e socioeconômico. Por judicialização das relações familiares compreende-se o movimento jurídico-institucional de regulação normativa, legal e burocrática da vida familiar, em que os sujeitos lançam mão de artifícios jurídicos com o objetivo de dar diligência aos conflitos de ordem emocional e afetiva, reproduzindo uns com os outros, em suas relações, dispositivos de controle, julgamento e punição das condutas. Trata-se de um mecanismo de poder, controle e 
coerção que permite, por exemplo, a criminalização das relações familiares e, com isso, um jogo político que atualiza, nas famílias contemporâneas, uma composição de forças e lógicas do Estado Penal (FOUCAULT, 2009). Para compreender o mecanismo de judicialização e criminalização das relações familiares, objetiva-se identificar, brevemente, algumas linhas que dão legitimidade à culpabilização e/ou patologização de determinados membros da família em prol do paradigma dos direitos individuais de um dos genitores, muitas vezes em detrimento dos direitos da criança e do adolescente. Movidos pelos estudos de Michel Foucault, Gilles Deleuze e Félix Guattari, a presente proposta visa produzir uma narrativa acerca das famílias de forma a compor com forças diferentes daquelas colocadas pela lógica judicante, de responsabilização unilateral de supostos genitores alienadores. Dessa forma, pretende-se situar a questão no contexto em que a figura do alienador apresenta-se como mais uma peça de um complexo jogo de forças.

$\mathrm{Na}$ esteira dessa discussão, a relevância do estudo se encontra na reflexão acerca da criminalização e da patologização da alienação parental, de forma a avançar na compreensão dos seus efeitos na vida das famílias e, com isso, contribuir para combater as lacunas ainda existentes na criação de sistemas de apoio, de suportes psicossociais, de estratégias e de políticas públicas que favoreçam o exercício da parentalidade após a separação conjugal. A partir dessa proposta, espera-se contribuir com o avanço da produção técnica e teórica como base para atuação do psicólogo na interface com a justiça, evitando-se que a psicologia se reduza às demandas por judicialização e patologização das relações familiares, não perdendo de vista seu compromisso ético e social com as pessoas envolvidas e a sua responsabilidade na promoção dos direitos das crianças e dos adolescentes.

\section{Método}

Participaram desta pesquisa 12 sujeitos, 10 homens e 2 mulheres que romperam o laço conjugal há, no mínimo, 1 ano e, no máximo, 10 anos, e que fazem parte de comunidades virtuais que abordam os temas guarda compartilhada e alienação parental na rede social conhecida como Facebook. 
Tabela 1: Caracterização dos participantes

\begin{tabular}{|c|c|c|c|c|c|c|}
\hline \multirow[t]{2}{*}{ Pais } & \multirow[t]{2}{*}{ Idade } & \multirow[t]{2}{*}{$\begin{array}{c}\text { Tempo de } \\
\text { união / } \\
\text { separação } \\
\text { (em anos) }\end{array}$} & \multicolumn{2}{|c|}{ Filhos } & \multicolumn{2}{|c|}{ Tipo de Guarda } \\
\hline & & & Sexo & Idade & Compartilhada & Exclusiva \\
\hline João & 39 & $2 ; 1$ & $\mathrm{~F}$ & 2 & - & Materna \\
\hline Eduardo & 43 & $7 ; 7$ & $\mathrm{M} ; \mathrm{F}$ & $12 ; 10$ & - & Materna \\
\hline Miguel & 54 & $10 ; 5$ & $\mathrm{~F}$ & 13 & - & Materna \\
\hline Mateus & 43 & $7 ; 6$ & M. & 12 & - & Materna \\
\hline Ernani & 52 & $6 ; 6$ & F & 8 & - & Materna \\
\hline Renato & 39 & $7 ; 3$ & $\mathrm{M} ; \mathrm{F}$ & $9 ; 4$ & - & Materna \\
\hline Vinícius & 39 & $3 ; 2$ & F & 3 & - & Materna \\
\hline Felipe & 41 & $7 ; 2$ & M & 14 & - & Materna \\
\hline Júlio & 36 & $1 ; 4$ & F & 4 & - & Materna \\
\hline Patrícia & 39 & $17 ; 2$ & $\mathrm{~F} ; \mathrm{M} ; \mathrm{M}$ & $16 ; 12 ; 9$ & $\operatorname{sim}$ & - \\
\hline Otávio & 35 & $3 ; 3$ & $\mathrm{~F} ; \mathrm{F}$ & $7 ; 4$ & - & Materna \\
\hline Eduarda & 40 & $7 ; 7$ & $\mathrm{~F} ; \mathrm{F}$ & $14 ; 15$ & - & Mat./Pat. \\
\hline
\end{tabular}

As comunidades virtuais foram escolhidas em função de sua atuação como uma espécie de grupo de apoio para pais e mães que declaram ter sofrido ou estar sofrendo alienação parental, bem como para pais que brigam na justiça para obter a guarda compartilhada dos filhos. Os grupos virtuais são comunidades fechadas e, por este motivo, a identidade dos grupos foi preservada. $\mathrm{O}$ convite para participar da pesquisa foi feito individualmente para 50 pessoas (25 homens e 25 mulheres), por meio de mensagens instantâneas - Messenger. Apenas 12 pessoas, 10 homens e 02 mulheres responderam. As entrevistas foram realizadas entre abril e outubro de 2017. Todos foram informados sobre os objetivos da pesquisa e sobre o procedimento de entrevista online. O projeto foi aprovado por um Comitê de Ética em Pesquisa. 
Todos os participantes assinaram o Termo de Consentimento Livre e Esclarecido e os nomes aqui apresentados são fictícios. O texto dos entrevistados, registrado por meio do Messenger, foi estimado a partir de uma inspiração nas ferramentas para uma ontologia do presente e do pensamento genealógico de Michel Foucault. A análise se deu de forma a fazer emergir os diagramas das relações, os enfrentamentos e cruzamentos de forças, os jogos de verdade, as enunciações e representações (FOUCAULT, 2005) postas em redes de agenciamentos que compõem a vida das famílias em litígio. Nessa perspectiva, a presente pesquisa presta-se à análise e desmontagem de artifícios e dispositivos de subjetivação e objetivação como uma máquina de resistência e liberdade (DELEUZE; GUATTARI, 1995).

Como instrumento de investigação, utilizou-se uma entrevista online com roteiro semiestruturado, contendo 15 questões abertas, composta pelos seguintes eixos temáticos: 1) conjugalidade; 2) convivência familiar pós divórcio; 3) divórcio judicial e guarda compartilhada; 4) alienação parental e criminalização da alienação parental. Analisamos as narrativas cartografando-as de forma convergente à análise de conteúdo (BARDIN, 2011). No trabalho de análise, propomos a divisão em estratos-eixos no qual o foco para o pesquisador ou para o grupo entrevistado foi mapear, compreender e autoanalisar os processos experimentados e o regime de forças ali presente. Para alcançar os objetivos deste artigo, foram discutidas as seguintes categorias-estratos-eixos: 1) Alienação Parental: uma patologia ou um fenômeno social; e 2) Criminalização da alienação parental.

\section{Discussão}

\section{Alienação Parental: uma patologia ou um fenômeno social?}

A alienação parental faz parte de um repertório de conflitos que marcam os relacionamentos íntimos, especialmente quando, em caso de separação, o confronto acaba por marcar o cotidiano das famílias. Os desacordos, por sua vez, instalam uma incompatibilidade permanente e incluem os filhos nesse jogo de poder que exige dos mesmos a escolha por um dos lados. Na narrativa dos participantes da pesquisa, destaca-se a campanha de desqualificação de um dos genitores como uma conduta presente no cotidiano com os filhos.

A campanha difamatória contra mim foi tão feroz que eu pensei que eu fosse enlouquecer. Não ter o respeito da minha filha e ver o meu amor por ela sendo afetado não foi fácil. Mas não gosto de repetir o que ela me dizia naquela época da separação. Dói muito. Hoje ela ainda não quer me ver e não o sei o que ela diz sobre mim, não convivo com ela. (Miguel) 
Minha ex repetia sempre "teu pai não presta, ele não te ama mais, não veio te buscar". Mas ela fazia isso nos dias que não eram meus e minha filha acreditava. Ela era muito pequena para entender na época. Achava que eu tinha abandonado ela. Tudo arquitetado. (Ernani)

Temos desenhado um mapa de conflitualidades que mascara, na alienação parental, a complexidade presente neste jogo de forças que se enuncia. Na narrativa de sofrimento dos pais destaca-se algo presente em Varas de Família, a saber, os casos em que pais e mães intencionalmente manipulam os seus filhos para se afastar e odiar o (a) outro (a) genitor (a). Por isso, faz-se importante destacar que, muitas vezes, o comportamento de um dos pais, ou de ambos, de desqualificação da figura do outro pode ser de ordem multifatorial. É neste sentido que se faz importante também evitar os esquemas maniqueístas, comuns nesse espiral de acusações que gira em torno de um ponto central: a suposta alienação parental. Emoções nebulosas, afetos de angústia, raiva e dor e uma narrativa denunciante revelam alguns dos nós que caracterizam o eixo dos litígios familiares: afasta e aproxima pais e filhos e os guia em movimentos que deixam à mostra essa engrenagem conflitiva.

Na presente análise, observa-se que, quando as disputas terminam em litígio, elas podem produzir um esgotamento e sofrimento mental de todos aqueles que estão imersos nesta situação conflitiva e, em meio a inúmeros conflitos, pode haver a redução da capacidade de atenção dos pais para responder às demandas do meio ambiente, às demandas dos filhos e às suas próprias (SEGURA, GIL, SEPULVEDA, 2006). Essa maquinaria conflitiva afeta o contexto da convivência familiar e pode levar os responsáveis à negligência dos cuidados com os filhos e da proteção dos mesmos, assim como pode afetar o direito da criança à convivência saudável com ambos os pais.

O prejuízo dos vínculos parentais apareceu nas falas de alguns dos entrevistados como uma das dificuldades relacionadas ao afastamento de um dos genitores. Muitas vezes, esse afastamento incluía a família desse genitor, especialmente os avós.

Ela proibia até que eu levasse meus filhos na casa dos meus pais. (Vinicius)

Ela não afastou apenas a mim, mas também a minha família. A minha mãe chora sempre e fala que queria ver a neta, pergunta se minha filha poderá vir na páscoa, no natal. Mas é impedida também de ver ela. A mãe não deixa a menina visitar a avó e chega a dizer que é porque ela é porca que a casa da minha mãe é suja. (João)

As alterações na dinâmica familiar após a separação conjugal e o redirecionamento das necessidades cotidianas de cada membro da família podem incluir alterações na rotina dos filhos e na sua interação com a família extensa do genitor não residente. É comum o afastamento 
entre a criança ou adolescente e a família do genitor com quem a criança não mais compartilha a casa, nos casos em que há guarda unilateral. A convivência e a participação dos avós na vida dos netos após o divórcio costumam sofrer mudanças e, muitas vezes, o afastamento entre eles acaba por afetar o dia a dia das famílias. Por outro lado, é comum que os avós por parte do genitor residente assumam responsabilidades de cuidados físicos, emocionais e financeiros (RODRIGUES, 2013). Dias, Hora e Aguiar (2010) ressaltam a responsabilidade dos avós nos cuidados com os netos e destacam que a concepção dos filhos sobre a participação dos avós em suas rotinas de vida é favorável e expressa boa qualidade de vida, especialmente quando os cuidados são compartilhados entre pais e avós. As autoras apontam que os filhos criados por avós com a participação de um ou ambos os pais estabelecem laços de afeto, carinho e respeito, os quais estão relacionados com a maturidade dos filhos. Para Kemp (2007), as transformações históricas, culturais e demográficas, bem como as circunstâncias familiares e individuais revelam mudanças nas dinâmicas sociais e familiares ao longo do tempo, produzindo novos padrões de relacionamento entre avós e netos de cada geração. Para o autor, não apenas o divórcio, mas também um novo relacionamento pais-padrastos-madrastas influencia diretamente o relacionamento avós-netos, afetando a dinâmica familiar. Com isso, observa-se a indissociabilidade entre vida e dinâmica familiar, posto que uma diversidade de fatores afeta a rotina das famílias pós divórcio e leva-as a uma necessária reorganização social, também subjetiva. Incluir o outro genitor e sua família de origem na rotina dos filhos exige, de ambos os pais, a capacidade de escuta e acolhimento dos filhos na dimensão da parentalidade. Os conflitos podem ser saudáveis na medida em que, diante dos impasses, o ex-casal encontre diferentes formas de relacionamento e convivência, produzindo, a partir da experiência, novos sentidos para os conflitos que se colocam, sentidos que transformem a composição de forças tal como ela se apresenta naquele momento. O divórcio pode servir como um analisador das relações familiares e, com isso, produzir crise e mal estar, mas também outras formas de expressão das relações a partir do exercício do cuidado. O conceito de analisador, forjado no movimento institucionalista francês (BAREMBLIT, 2002), é entendido como um catalisador de sentido, capaz de expor silêncios, saberes e práticas de uma comunidade - ou de uma família em conflito - sobre si mesma, o que produz a desnaturalização dos modos de ser e existir. Tratase de um dispositivo que revela, nos modos de funcionamento familiar, o impensado, o saber e o não saber sobre si mesma, os afetos ditos e não ditos que sustentam, por sua vez, nesta pequena estrutura social, a conformidade com modelos instituídos, que podem ser de casamento, 
parentalidade, filiação, família. Uma relação parental baseada na construção do cuidado é condição para a criação de outro corpo-expressão que se apresente e transforme o regime social, cultural e subjetivo, que insiste em dar lugar às mágoas e ressentimentos e, desta forma, conferir espaço aos filhos e as suas origens, a sua história, e, por que não, à presença e participação dos avós em suas vidas. O divórcio como analisador das relações familiares pode permitir que a vida persevere num processo constante de transfiguração, fazendo da experiência um processo de produção de um novo corpo em relação com o outro, em que a vida possa fluir.

Sobre o afastamento e impedimento à visita, a maioria dos participantes relatou ter vivenciado longo tempo sem ver o (s) filho (s).

Eu não tenho convívio com a minha filha. O número do celular que ela mesma um dia me passou não existe. $O$ telefone residencial eu não tenho. Sei das coisas quando alguém me conta. Meu direito de visita nunca foi respeitado. Quando raramente eu consigo falar com a minha filha pelo telefone da mãe dela ela fala comigo assim: "eu odeio o meu pai, eu odeio o meu pai". Fala cantarolando. Fiquei mais de um ano sem saber nada dela na época da separação e tudo me era negado. Cheguei a pagar detetive para descobrir onde ela estava estudando porque a mãe mudou ela de escola nessa época sem falar nada comigo. (Miguel)

Atualmente faz 5 meses sem contato, apenas uma ligação no dia do aniversário deles. Nem na escola eu posso vê-los. Fui proibido. (Renato)

Quando eu chego na casa dela para o meu final de semana com ele, pra buscá-lo, ele nunca está e a mãe me recebe com uma desculpa qualquer, que ele não está, que foi para a casa do avô ou de um amigo e que não quer vir comigo. É assim desde a separação nunca mudou. Por isso eu cansei. (Felipe)

Brito (2007) ressalta, a partir de resultados de pesquisa com filhos adultos de pais separados, que a percepção do afastamento de um dos genitores e a tomada de consciência do fator preponderante dessa separação entre pais e filhos advinham da entrada na fase adulta. Somente nesse momento os filhos percebiam que o afastamento do genitor não residente estava atrelado às desavenças entre os pais, o que deixa evidente o quanto a conjugalidade e a parentalidade seguem unificadas, mesmo após a separação. Alguns atribuíram o não cumprimento da visitação, geralmente pelo pai, aos atritos da conjugalidade e aos arranjos da guarda exclusiva.

Para Segura, Gil e Sepulveda (2006), as situações que envolvem o afastamento de um dos genitores caracterizam uma obstrução, por parte de um dos pais, para impedir a fluidez da relação pai-filho. Não se pretende, aqui, nomear tal experiência como sendo uma alienação parental, como determinam os autores citados. Contudo, é válido dizer que, diante da legislação 
em vigor, existe um respaldo da justiça que caminha na tentativa de frear as manipulações da (o) genitor (a) que deliberadamente afasta o seu filho do outro. O afastamento existe, mas a sanção judicial deve ser o último recurso na busca pela garantia do direito da criança à convivência familiar. Minorar o sofrimento da criança implica administrar, da melhor maneira possível, a manutenção do convívio com ambos os pais. É importante lembrar que o repúdio de uma criança a um dos pais ou a ambos pode envolver outras dimensões de dor e sofrimento. A criança pode não desejar a aproximação e ter motivos para tanto. Bem como pode estar em sofrimento não porque não deseja o contato, mas porque não tem permissão ou não se sente confortável para manifestar afeto e dizer o quanto deseja se aproximar do (a) genitor (a). O que se coloca, além disso, é o compartilhamento, com os filhos, dos conflitos que geraram a separação conjugal. Nesses casos, as crianças ficam imersas nos problemas dos adultos, e podem tomar partido no conflito, tornando-se parte das disputas dos pais.

As narrativas de anulação simbólica caracterizam, para os genitores não residentes entrevistados, uma barreira para a compreensão, por parte dos filhos, da sua importância na vida deles.

Ela proibia até os meus presentes. Me anulava da vida dos meus filhos. Quando eu pegava meus filhos e dava presentes eles falavam... Papai não posso levar...senão a mãe joga fora. Quantas vezes o mais velho levava as coisas escondidas na cueca...Coisas simples, figurinhas. É de cortar o coração. Parece que ela fazia de tudo para que eu não existisse na vida deles. (Renato)

Eu era proibido de tudo, de ver, sair com ele, de levar na minha casa, de buscar na escola, de dar presentes. Os presentes ela escondia, não sei o que acontecia, mas sumiam. A minha ex chegava a dizer ao meu filho que os meus outros dois filhos de outro relacionamento não eram irmãos dele. Ele rejeitava os irmãos que tentavam falar com ele e ele fingia que não via. Imagina uma criança de três anos falando com alguém que finge não a ver. Pra mim isso é uma morte simbólica e lenta. (Felipe)

Compreende-se que os cuidados parentais direcionados aos filhos ficam comprometidos à medida que as tarefas cotidianas dos pais junto aos filhos são influenciadas pela dimensão conflitual dos pais, podendo dificultar a prática da parentalidade. A prática da parentalidade diz respeito não apenas aos cuidados físicos, mas também aos cuidados psíquicos e socioafetivos direcionados pelos pais aos filhos (HOUZEL, 2004). Essa prática de cuidado pode ser afetada caso o modo de interação entre pais e filhos sofra privação, isto é, quando os cuidados parentais ficam subjugados à carência de uma potência afetiva capaz de produzir novos agenciamentos e, assim, mobilizar as afecções tristes, que rebaixam a vida (DELEUZE, 2002). Ou seja, quando o processo de divórcio codifica as experiências dos pais na lógica da conflitualidade, ele reduz 
a potência afetiva do cuidado na relação parental. E como é possível um processo de interação familiar pós divórcio capaz de evocar a grande saúde em tempos de afirmação dos conflitos? É importante reconhecer que, em meio às adversidades da separação conjugal conflituosa, há também um funcionamento familiar que leva os pais a uma prática sobreimplicada, em que o individualismo se faz presente, as parcerias e alianças se fragilizam e esvaziam-se, assim como os espaços coletivos de construção do plano comum. A sobreimplicação é "a ideologia normativa do sobretrabalho" (LOURAU, 2004a: 190), ligada, em consonância, à crença no ativismo das práticas e no acúmulo de tarefas, sem, no entanto, permitir dar lugar à análise de implicação, isto é, uma análise coletiva da situação presente e todas as condições que a envolvem (LOURAU, 2004b: 256). Nesta lógica, os genitores podem ficar submersos em uma prática parental solitária, ativista, excludente do outro genitor e, com isso, tomada por um acúmulo de tarefas que sobrecarrega, principalmente, o genitor residente. Eliminar o outro genitor da vida dos filhos pode significar, dentre tantas outras possibilidades e conjunturas, a ineficácia das redes de parcerias e, portanto, as dificuldades no enfrentamento de situações de violência que podem advir dos processos conflitantes.

\section{Criminalização da Alienação Parental}

A busca pela punição do genitor alienante foi destaque na narrativa de 10 dentre os 12 participantes da pesquisa. Muitos compararam a criminalização da alienação parental com a criminalização do não pagamento da pensão alimentícia.

Sou favorável à criminalização, mas antes é preciso modificar a conscientização dos tribunais e acabar com a ideia de que só o homem é culpado. Se o devedor da pensão vai para a cadeia acho que os males da alienação parental também deveriam ser criminalizados. Seria uma medida coibidora e faria com que o alienador tivesse medo de ir preso. Ela deveria pagar por tudo que fez a mim e a minha filha. (Ernani)

Eu acho que a criminalização é um fator importante, tem que ser punido de verdade, não pode sair impune. Ela saiu impune em termos de justiça, mandaram ela fazer um monte de coisas e ela não fez e continuou fazendo o mesmo comportamento, de alienação e mesmo assim ela tem a imagem de que ganhou o processo e não é justo. Mas ela tem que ser punida, tem que ser privada de liberdade, ela cometeu um crime e é obrigação do estado recuperar ela, é dever do estado. O pai é criminalizado se não pagar a pensão, a mãe também pode ser por alienar. (Matheus)

Observa-se que, além da crença no sistema judicial como mediador dos conflitos, emergem, na narrativa dos entrevistados, questões relativas aos gêneros masculino e feminino. Nas falas dos participantes da pesquisa é ressaltada a criminalização de homens e mulheres 
como busca de igualdade e justiça. A mulher, socialmente reconhecida como cuidadora e, por isso, detentora da guarda deveria ser punida em caso de "imprimir" nos filhos a suposta alienação parental. Os homens, socialmente reconhecidos como provedores, quando não cumprem com o pagamento da pensão alimentícia, são criminalizados. De acordo com a legislação específica (BRASIL, 1968; 2015), o objetivo da criminalização do não pagamento da pensão alimentícia não é a punibilidade, mas a coação ao devedor, que é compelido a realizar o pagamento. Se o devedor não pagar, a justiça poderá decretar a prisão pelo prazo de um a três meses. Para a maioria dos entrevistados, esta seria uma criminalização injusta, uma vez que confere às prerrogativas da paternidade funções que ressaltam apenas a exigência de provisão material dos filhos. Ressalta-se que a legislação acerca da pensão alimentícia não diferencia gênero para a responsabilidade financeira em relação aos filhos. Deste modo, a narrativa dos entrevistados sinaliza o modo como os mesmos percebem os efeitos da legislação em seu cotidiano. Além disso, destaca-se, a partir dessas narrativas, os sentimentos de rancor e vingança que marcam as comparações entre criminalização da alienação parental e criminalização do não pagamento da pensão alimentícia.

Recorrer aos artifícios judiciais para obter a punição do genitor que comete a suposta alienação parental também pode ser um movimento nocivo para os filhos e indutor da ampliação dos conflitos. Além disso, destaca-se, com a criminalização da alienação parental, a produção de uma delinquência inútil (FOUCAULT, 2009), ou seja, a institucionalização de uma nova estratégia de punibilidade, característica do sistema prisional, que contribui não para o seu fracasso, mas para a composição de novos dispositivos de ilegalidade, ao identificar o tolerável e o intolerável, punindo aquele que transgrediu a nova regra imposta. O genitor alienador, sob a ótica de uma nova produção das ilegalidades, não é apenas um infrator qualificado por seu ato de alienação parental, mas caracteriza-se, eminentemente, como um delinquente (FOUCAULT, 2009), ou seja, sua biografia, doravante marcada pela lógica do Estado Penal, indica um conjunto de comportamentos, temperamentos, personalidade ou tendência criminosa escondido à sombra do delito cometido. Interessa ao Estado Penal a revelação do criminoso por detrás do infrator e, com isso, a expansão e pulverização, no campo social, dos muros da prisão. São as Varas de Família garantindo não o bem-estar dos sujeitos enredados em histórias conjugais e familiares em lide, mas a gestão policialesca das vidas a partir da ampliação da teia punitivista. É a justiça penal permeando as Varas de Família para exacerbar os conflitos. A ação dos especialistas que atuam no Direito pode contribuir amplamente para o aprofundamento 
dessa lógica. Quando os conflitos são intensificados - por exemplo, quando há o impedimento do direito de visita -, sentimentos de ódio e vingança podem motivar os genitores a estratégias de punição do ex-parceito (a). O sistema judicial, com a intervenção de advogados, juízes, psicólogos, assistentes sociais, pode acentuar o sentimento de aversão a um dos genitores, desencadeando acusações e diagnósticos precipitados. O lugar privilegiado que ocupa o Poder Judiciário na administração da lide pode fazer com que ele se torne parte do jogo de forças, incluindo-o no enredo conflitual como um elemento principal que poderá favorecer os conflitos ou agravá-la (ANTUNES, MAGALHÃES, FÉRES-CARNEIRO, 2010). Além disso, atentase para o papel do exercício do poder, controle e coerção estatal notadamente presentes no ideário punitivista.

No âmbito do Direito de Família é preciso focar na formulação de leis que estejam em harmonia com os direitos das crianças e adolescentes e com os fundamentos constitucionais. Tal ponto foi evocado por apenas dois genitores entrevistados.

Eu não sou a favor da prisão nos casos de alienação parental, porque isso marcaria muito a criança também. Eu acho que uma terapia de casal, mesmo com o casal separado, ajudaria muito. E seria em favor da criança. Acredito mais nisso. (Felipe)

A criminalização não é o que eu almejo no momento. Acho que não ajudaria em nada. Eu só queria poder conviver com a minha filha e que meus pais também tenham esse direito e nada mais. (João)

Assim, o ideal punitivista de criminalização da alienação parental deixa uma série de lacunas no que tange à construção de estratégias de suporte social para as famílias em litígio, uma vez que se limita apenas à judicialização das relações familiares. Seus efeitos podem refletir-se em políticas regulatórias. Ressalta-se que, muitas vezes, a alienação parental é compreendida de forma a-histórica e descontextualizada, desconsiderando o percurso históricocultural que ofereceu à mulher o papel social de cuidadora e ao homem, o de provedor.

Para pensar os processos de subjetivação que engendram corpos e modos de ser ditos masculinos ou femininos, é importante destacar a produção histórica do modelo de maternidade. Como apontado por Donzelot (1980), não se deve esquecer que a medicina social, como uma estratégia de gestão da vida, revelou-se fundamental para a constituição da família moderna/nuclear como um ideal a ser seguido. Com o nascimento da família nuclear, em meados do século XVIII, na Europa, emerge um novo tipo de gestão da vida, um novo modo de gerir as populações, à medida que as mudanças comportamentais eram administradas pela via intrafamiliar, com o auxílio da mulher/mãe, produzindo, dentre outras coisas, o domínio das 
práticas educacionais, de saúde, sexuais e o controle demográfico. A mulher burguesa se tornou a difusora do saber médico e o cuidado com as crianças passa a ser tema importante na literatura médica, objeto de preocupação e intervenção estatal. Houve uma capilarização de estratégias de controle dos corpos-maternos que dirige um modo de ser mãe contemporâneo, através de discursos hegemônicos (RAGO, 1985; BADINTER, 2011).

Como apontado por Sousa (2010), as alianças parentais sempre existiram e, especialmente no contexto de separação conjugal, podem provocar sofrimento a todos os envolvidos. No entanto, ressalta a autora, é preocupante a difusão do tema da alienação parental de forma descontextualizada, uma vez que o alarde em torno do assunto fortalece imagens distorcidas dos ex-cônjuges, como, por exemplo, do genitor alienador, comumente visto como uma espécie de monstro que precisa ser punido. Na alienação parental, associado à figura da mulher, considerando que é a mãe quem geralmente fica com a guarda exclusiva dos filhos, o genitor alienador torna-se o vilão da história. É importante lembrar que, nesta pesquisa, o número de entrevistados foi composto, em sua maioria, por sujeitos do sexo masculino. Homens que, possivelmente, são socialmente reconhecidos como provedores, em oposição às mulheres, na maioria das vezes, guardiãs dos filhos no processo de separação conjugal e socialmente identificadas como cuidadoras mais adequadas. Com isso, observa-se um processo não apenas familiar, mas histórico e social, de estigmatização de mulheres, que são vistas como egoístas por restringirem, por diversos e distintos motivos, o convívio entre o pai e o (s) filho (s).

Considerando os conflitos que se estabelecem entre os ex-cônjuges em situação de litígio, é preciso reconhecer que lidar com tais desavenças envolve considerar que as famílias demandam uma resolutividade que não cabe ao Poder Legislativo e/ou Judiciário. Caso aceitem esse papel, as instituições podem acabar por auxiliar a perpetuação do litígio. Disposto à dissolução da conflitualidade, o Poder Judiciário deve considerar que a demanda jurídica está fortemente arraigada nas questões afetivas, angústias e ansiedades advindas da experiência do divórcio. E que as decisões estarão sempre sujeitas ao risco da injustiça, por mais criteriosos que sejam os profissionais, inclusive da área de psicologia, envolvidos no processo de avaliação da situação familiar.

Na pesquisa, a narrativa de alguns dos pais entrevistados destacava as suas crenças na criminalização e na restrição de liberdade como sendo a única saída para dar cabo ao comportamento alienante. 
Tem que colocar na cadeia. Tá certo que que o sistema penitenciário brasileiro é complicado, então eu não quero que ela fique numa cela com um traficante, com um bandido, não. Mas ela tem que ser punida, tem que ser privada de liberdade. (Vinícius)

Acho que a prisão seria a pior das hipóteses, uma multa primeiro e em casos de reincidência, utilizaria a privação de liberdade. (Renato)

A PL 4488/2016 não visa a prisão de imediato, esse ponto é importante. Mas mesmo em último caso ela deve existir como um elemento coibidor. (Júlio)

A busca pelo enfraquecimento do comportamento alienante a partir de uma medida punitiva para o genitor alienador contrasta com o alinhamento por justiça, convivência familiar e diminuição da lide. A punição do comportamento alienante é retomada em uma proporção ampliada do desejo de vingança do genitor alienado. Alguns pais reconhecem os efeitos nocivos do Sistema Penal brasileiro, mas não concluem daí que este seria essencialmente prejudicial para os filhos e a família. Observa-se que o sentimento de ressentimento e vingança é um dos vetores que move a luta dos pais pela criminalização da alienação parental. A visão punitivista, que pressupõe que a resolutividade da situação conflituosa se encontra na esfera criminal e não nas Varas de Família, está acoplada a uma dimensão do poder que produz, na arena da família, uma divisão maniqueísta que considera apenas culpados, vítimas e inocentes, produzindo ciclos punitivos intermináveis.

A judicialização das relações familiares atribui aos pais um adjetivo punitivista - os alienadores parentais - capaz de promover o desejo de vingança, já que conduz a uma lógica adversarial que insere a justiça no contexto do litígio (ANTUNES; MAGALHÃES; FÉRESCARNEIRO, 2010) a partir de um jogo fundamentado na persecutoriedade e na culpa (GROENINGA, 2003). Esse jogo de forças faz com que as famílias sejam permanentemente convocadas a contracenar junto à justiça, sustentando a perpetuação dos litígios (ANTUNES; MAGALHÃES; FÉRES-CARNEIRO, 2010), a lógica de poder (FOUCAULT, 2005; 2006, 2009) e a aliança entre a família e o Estado Penal.

\section{Considerações finais}

A partir dos objetivos propostos pela pesquisa, foi possível perceber que a chamada alienação parental é caracterizada por um fenômeno social que faz parte de um repertório de desacordos, incompatibilidade e conflitos entre os pais que, ao enredar situações de litigância, incluem os filhos em um jogo de poder que, muitas vezes colabora para que crianças e 
adolescentes convivam apenas com um dos genitores e suas respectivas famílias extensas, deixando um dos pais alijado de sua função parental. O Poder Judiciário, por sua vez, favorece os processos de medicalização, patologização, judicialização e criminalização da família, já que frequentemente atua como um emissário do mal-estar, intensificando os conflitos familiares a partir de um jogo político fundamentado na lógica da punibilidade e da culpa. Como narrado pelos participantes da pesquisa, a campanha de desqualificação de um dos genitores é capaz de provocar dor e sofrimento. E a interferência inoportuna da justiça caminha junto com a exacerbação da lide, contribuindo para a perda da convivência dos filhos com um de seus progenitores. Apontaram os entrevistados que as alterações na dinâmica familiar pós-divórcio e as características de acentuação da lide contribuíram para o afastamento do genitor não guardião e de sua família, especialmente os avós. Nesse sentido, observa-se que a separação conjugal estendeu-se à separação dos filhos. Os cuidados parentais ficam comprometidos à medida que a desestabilização no relacionamento parento-filial se acentua com as dimensões de conjugalidade e parentalidade embaçadas.

Resultado de processos de produção de modos de existência, a alienação parental é fruto dos laboratórios dos tribunais de família norte-americanos e, sendo assim, a expressão Síndrome da Alienação Parental contribuiu intensamente para a patologização da vivência conflitual nas famílias pós-divórcio que, diante das dificuldades impostas pela partida de um dos cônjuges, manifesta confusão entre as questões relativas ao exercício da conjugalidade e da parentalidade. Sabe-se que a teoria da SAP de Gardner revelou-se inconsistente do ponto de vista médico-psiquiátrico, já que não cumpre os requisitos nosológicos para a identificação e classificação da suposta patologia. Neste sentido, é de fundamental importância a análise da alienação parental como um fenômeno histórico e social que deve ser visto em suas nuances e camadas que recobrem o contexto familiar. É de fundamental importância, portanto, não perder de vista o contexto social, político e econômico no qual se insere a alienação parental, destacando-se a necessidade de construção de políticas públicas que atuem no apoio às famílias e não na responsabilização de indivíduos e na busca pelos culpados. É preciso, então, superar o modelo norte-americano de Gardner, que privilegia a nosologia médica e sua correspondente medicalização da vida familiar e, com isso, o tratamento comportamental e a culpabilização individual dos sujeitos considerados alienadores.

Quando há separação conjugal sem acordo quanto ao novo direcionamento das questões familiares, é comum a procura pelo Poder Judiciário para que este dê diligência às dificuldades 
encontradas pelo ex-casal em administrar as situações de litigância. Não raro, buscam apoio junto à justiça na esperança de que as questões de ordem psíquica sejam também resolvidas naquele espaço, delegando ao suporte judicial a condução do mal-estar que advém do divórcio. Esta tendência conduz ao fenômeno da judicialização da família, através do qual o Judiciário, no intuito de garantir os direitos fundamentais, principalmente dos filhos, é convocado a exercer uma função de controle que, muitas vezes, contribui para a perpetuação do vínculo conjugal através da manutenção da lide.

Ressalta-se que, historicamente, cada época estabelece um regime de verdade em torno do que se convenciona como punível ou não na esfera familiar e, com isso, um perfil de normalidade e de anormalidade. Desta forma, estereótipos vigoram em torno de uma norma, direcionando não apenas um determinado modo adequado de experiência para a convivência entre membros de uma família, mas modos de prescrição de comportamento que pretendem alçar a prevenção de uma suposta disfuncionalidade familiar, que englobam um funcionamento coletivo (FOUCAULT, 2006). É preciso ajustar as famílias a um modelo ideal vigente. Para Foucault (2006, p. 141), “é bastante evidente, em suma, que o custo do diabetes e da arteriosclerose é ínfimo se comparado às despesas ocasionadas pelo tabagismo e pelo alcoolismo". Haveria também um custo socioeconômico para o Estado em relação às famílias que litigam e disputam, na justiça, o direito à prática da parentalidade? Ou haveria lucro em torno da emergência dos tribunais contemporâneos de judicialização dessas relações familiares? Qual o papel da justiça nessa conjuntura social/institucional?

Destaca-se que a alienação parental está vastamente filiada ao litígio e, caso o poder Legislativo decida entrar no jogo de forças que compõem esse palco de disputas, retomando Projetos de Lei como a PL 4488/2016 que criminalizam a alienação parental, caberá ao Poder Judiciário o papel de ampliação da judicialização da vida. Observa-se que a criminalização do comportamento alienante provavelmente não resultará em medidas de garantia dos direitos das crianças e dos adolescentes. Nesse sentido, questionam-se os limites do legislativo e também do judiciário na composição de uma intervenção junto às famílias e as estratégias de judicialização das relações familiares. A tarefa das instituições não pode ser a de sedimentação do litígio nos processos.

Considerando as forças de configuração familiar pós-divórcio conflitivo, parece sugestivo arriscar uma abordagem que permeie as dificuldades que atravessam as famílias a partir de uma intervenção psicossocial e terapêutica, que sirva como suporte para aqueles que 
se encontram em situação de litígio. A conflitualidade familiar tende a ser cronificada quando recebe intervenção exclusivamente judicial. Portanto, a colaboração entre sistemas de apoio e suportes psicossociais é indispensável para a obtenção de resultados satisfatórios para as famílias, não cabendo o posicionamento patologizante, medicalizante, judicializante e/ou criminalizante dos conflitos conjugais, mas estratégias e políticas públicas - na Educação, Assistência Social e Saúde - que favoreçam o exercício da parentalidade e não da judicialização da vida.

Destaca-se que, a respeito de alienação parental, consideramos ser inviável abordar um tema tão complexo em sua totalidade. A própria identificação da alienação parental, como previsto na legislação vigente sobre o tema (BRASIL, 2010), mesmo com equipes transdisciplinares, é arriscada e vacilante. Não existem fórmulas específicas que possam dar diligência a todas as situações denunciadas e há sempre o risco de constituir, junto aos sujeitos envolvidos no processo, uma relação maniqueísta, capaz de promover dualismos, de marcar lugares de culpados ou inocentes. O reforço de uma posição dual irredutível faz emergir, não apenas nos processos de judicialização, mas também nos processos de subjetivação, identidades encerradas na lógica do antagonismo, que inclui as famílias em litígio numa suposta luta do bem contra o mal e que faz produzir no mundo uma visão representacional de família pós divórcio dividida entre poderes opostos e incompatíveis: o do pai e o da mãe.

Além disso, com a acentuação de dispositivos sociais de tutela e controle sobre as famílias judicializadas, desnudam-se narrativas de compreensão muitas vezes misógina e, com isso, a culpabilização da mulher pelo domínio da esfera doméstica, quando a mesma foi historicamente socializada para ocupar tal lugar de controle ou gestão, mas também de cuidado com a casa, os filhos, o marido e a família. O discurso denunciante, longe de ser um elemento transparente ou neutro, e que coloca a mulher no lugar de suspeita da suposta alienação parental, não traz à tona apenas as lutas ou os sistemas de dominação masculina, mas, naquilo pelo que se luta descortina-se o poder do qual se quer apoderar, isto é, o poder sobre a mulher, seus hábitos, seus comportamentos, sua administração da prole e das famílias em litígio ou não.

Como sinaliza Foucault (2005), os discursos se ligam às interdições que, por sua vez, colocam em jogo o desejo e o poder. Permeado por um sistema de exclusão, o discurso sofre proibições, segregações e uma vontade de verdade. Neste trabalho, o desnivelamento entre o número de mulheres que aceitaram participar da pesquisa e o número de homens que se prontificaram para tal - num universo de 50 sujeitos, 10 homens e 02 mulheres - nos permite 
observar uma pista acerca da construção dessas narrativas: elas são contadas, repetidas, variadas e ritualizadas conforme uma circunstância determinada, a saber, a do mundo do divórcio na vida dos homens. O homem, historicamente narrador dos discursos tidos como fundamentais, absolutos, constantes e estáveis. As narrativas de alienação parental se deslocam entre o discurso fundamental da dominação masculina e a "massa daqueles que repetem, glosam e comentam" (FOUCAULT, 2005, p. 23). Com isso, observa-se um desnivelamento radical entre homens e mulheres nesse jogo de forças em que se institui a construção das narrativas acerca da família pós divórcio em disputa pela prole. A palavra masculina encerra um inesgotável tesouro de sentidos, é o enunciado de uma riqueza e de um segredo absolutos que reivindica pra si o renascimento de um novo domínio da esfera doméstica, que é o do cuidado com os filhos. O homem-pai deseja participar da criação, da rotina e do cuidado. Para isso é relançado no mundo uma cadeia de sentidos que expressa o desejo e o poder, mascarados em discursos de direitos, de garantir a manutenção do novo pai nesse novo modelo de família: a família pós divórcio, desde a sua emergência regulada pelo Estado. O discurso do pai presente renasce absolutamente novo e imaculado em cada um de seus pontos e reaparece na produção de sentidos, sentimentos e pensamentos. Pai, mãe e filhos constituem relações no mundo que não cessam de se modificar através do tempo e que ganham formas múltiplas, divergentes, ocultas, reticentes, mas também fundamentais, já que é na família que se reforçam as narrativas de fundação do humano, seu texto primeiro, sua origem e autoria.

O denuncismo à experiência da alienação parental induz à análise precipitada de que a resolutividade da situação complexa e adversa deve ser permeada pela esfera criminal e não civil. O manejo de questões familiares, cuja matéria envolve aspectos subjetivos, sociais, jurídicos, econômicos e políticos, coloca em xeque todo processo de judicialização e medicalização das relações familiares, e exige de nós, profissionais, um olhar clínico apurado e comprometido com a potencialização da vida. Ademais, é preciso também apontar os limites deste estudo, de modo a ressaltar que se trata de um recorte, e que, portanto, o conteúdo aqui apresentado não é capaz de expressar a totalidade das concepções socialmente vigentes acerca dos debates favoráveis à judicialização das relações familiares ou da vivência/criminalização da alienação parental, sendo o presente estudo apenas uma contribuição ao campo. Da mesma forma, é importante destacar as limitações perante as condições de emergência das narrativas dos participantes desta pesquisa, considerando as especificidades dos sujeitos imersos em situações de lide no sistema de justiça. 


\section{Referências}

ANTUNES, Ana Lúcia Marinômio de Paula; MAGALHAES, Andrea Seixas.; FÉRESCARNEIRO, Terezinha. Litígios intermináveis: uma perpetuação do vínculo conjugal? Aletheia [online]. 2010, n. 31, PP. 199-211. ISSN 1412-0394.

BADINTER, Elisabeth. O conflito: a mulher e a mãe. Rio de Janeiro: Record, 2011.

BARDIN, Laurence. Análise de conteúdo. São Paulo: Edições 70, 2011.

BAREMBLIT, Gregório Franklin. Compêndio de Análise Institucional e outras correntes: teoria e prática. Belo Horizonte, MG: Instituto Félix Guattari, 2002.

BOLAÑOS, Ignacio. Hijos Alienados y Padres Alienados. Asesoramiento e Intervención en las Rupturas Conflictivas. Revista del Colegio de Trabajadores Sociales de Madrid, Madrid, v.1, n.1, p. 105-123, 2005.

BRASIL, Projeto de Lei ${ }^{\circ}$ 4.488, de 2016. COMISSÃO DE SEGURIDADE SOCIAL E FAMÍLIA, $2017 . \quad$ Disponível em // http://www.camara.gov.br/proposicoesWeb/prop_mostrarintegra;jsessionid=0E07 B3E007414E760CF9D71F1E772BAB.proposicoesWebExterno2?codteor $=1594677$

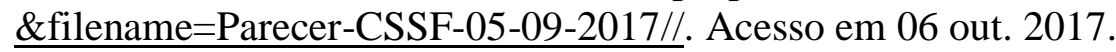

BRASIL. Alienação parental. Lei ${ }^{\circ} 12318$, de 26 de agosto de 2010. Dispõe sobre a alienação parental e altera o art. 236 da Lei no 8.069, de 13 de julho de 1990. Brasília, 2010.

BRASIL. Lei de Alimentos. Lei no 5478, de 25 julho de 1968. Dispõe sobre ação de alimentos e dá outras providências. Brasília, 1968.

BRASIL. Código de Processo Civil. Lei no 13105, de 16 de março de 2015. Dispõe sobre as normas processuais civis. Brasília, 2015.

BRITO, L. M. T de. Família pós-divórcio: a visão dos filhos. Psicologia, ciência e profissão, Brasília, v. 27, n. 1, p. 32-45, 2007. http://dx.doi.org/10.1590/S1414$\underline{98932007000100004 .}$

CANGUILHEM, Georges. O normal e o patológico. $5^{\mathrm{a}}$ ed. Rio de Janeiro: Forense Universitária, 2002.

DELEUZE, Gilles. Espinosa: filosofia prática. Trad. Daniel Lins e Fabien Pascal Lins. São Paulo: Escuta, 2002.

DELEUZE, Gilles; GUATTARI, Félix. Mil Platôs: Capitalismo e Esquizofrenia (Vols. 1-5). São Paulo: Ed. 34, 1995.

DIAS, Cristina Maria de Souza Brito; HORA, Flávia Fernanda Araújo da; AGUIAR, Ana Gabriela de Souza. Jovens criados por avós e por um ou ambos os pais. Psicologia: teoria e prática, São Paulo, v. 12, n. 2, p. 188-199, fev. 2010.

DONZELOT, Jacques. A polícia das famílias. Rio de Janeiro: Graal, 1980. 
FERMANN, Ilana Luiz et al. Perícias Psicológicas em Processos Judiciais Envolvendo Suspeita de Alienação Parental. Psicol. cienc. prof., Brasília, v. 37, n. 1, p. 35-47, Jan. 2017. Disponível em <http://www.scielo.br/scielo.php?script=sci_arttext\&pid=S141498932017000100035\&lng=en\&nrm=iso>. Acesso em 10 Jan 2020. http://dx.doi.org/10.1590/1982-3703001202016.

FOUCAULT, Michel. Vigiar e punir: nascimento da prisão. Petrópolis: Editora Vozes, 2009.

FOUCAULT, Michel. O poder psiquiátrico. São Paulo: Editora Martins Fontes, 2006.

FOUCAULT, Michel. A ordem do discurso. São Paulo: Editora Loyola, 2005.

FOUCAULT, Michel. O nascimento da medicina social. In: FOUCAULT, Michel. Microfísica do Poder. Rio de Janeiro: Edições Graal, 1979.

GARDNER, Richard Alan. Denial of the parental alienation syndrome also harms women. The American Journal of Family Therapy. New York, USA, v. 30 (3), p. 191-202, 2002. Disponível em: <http://www.rgardner.com/refs/ar2.htm >. Acesso em: 10 set. 2017.

GARDNER, Richard Alan. Legal and psychotherapeutic approaches to the theree types of parental alienations syndrome families. When psychiatry and law join forces. Court Review, Commonwealth of Virginia, USA, v. 28, n.1, p.14-21, 1991. Disponível em: http://www.fact.on.ca/Info/pas/gardnr01.htm. Acesso em: 10 jun. 2015.

GONZALEZ, Marta Ramírez; CABARGA, Pilar de Luis; VALVERDE, Vicente Ibáñez. Percepciones Parentales en Ninõs de Famílias Separadas - una Nueva Versión Del Síndrome de Estocolmo? Anuário de Psicología Jurídica, Madrid, pp.25-43, 1994.

GROENINGA, Giselle Câmara. O direito a ser humano: da culpa a responsabilidade. In: GROENINGA, Giselle Câmara; PEREIRA, Rodrigo da Cunha (org.). Direito de Família e Psicanálise: rumo a uma nova epistemologia. Rio de Janeiro: Imago, 2003.

HOUZEL, Didier. As implicações da parentalidade. In: SOLIS-PONTON, Letícia (org). Ser pai, ser mãe: parentalidade: um desafio para o terceiro milênio. São Paulo: Casa do Psicólogo, 2004.

KEMP, Candace. Grandparent-grandchild ties: reflections on continuity and change across three generations. Journal of Family Issues, v. 28, p. 855-881, 2007.

LOURAU, René. Implicação e sobreimplicação. In: ALTOÉ, Sônia (org). René Lourau: Analista institucional em tempo integral. São Paulo: Hucitec, 2004a.

LOURAU, René. Implicação: um novo paradigma? In: ALTOÉ, Sônia (org). René Lourau: Analista institucional em tempo integral. São Paulo: Hucitec, 2004b.

NUSKE, João Pedro Fahrion; GRIGORIEFF, Alexandra Garcia. Alienação parental: complexidades despertadas no âmbito familiar. Pensando Famílias, Porto Alegre, v. 19, n. 1, p. 77-87, jun. 2015.

RAGO, Margareth. Do cabaré ao lar, a utopia da cidade disciplinar: Brasil 1890-1930. Rio de Janeiro: Paz e terra, 1985.

RODRIGUES, Sara Sofia Amaral. A relação entre pais e netos após a separação conjugal dos pais. Dissertação de Mestrado, Universidade de Lisboa, 2013. 
SEGURA, C.; GIL, MJ.; SEPULVEDA, Angeles. El síndrome de alienación parental: una forma de maltrato infantil. Cuad. med. forense, Málaga, n. 43-44, p. 117-128, abr. 2006.

SILVA, Rosane Neves da. A invenção da psicologia social. Petrópolis: Editoras Vozes, 2005.

SOUSA, A. M. Síndrome da Alienação Parental: um novo tema nos juízos de família. São Paulo: Editora Cortez, 2010.

SOUSA, Analícia Martins de; BRITO, Leila Maria Torraca de. Síndrome de alienação parental: da teoria Norte-Americana à nova lei brasileira. Psicologia ciência $e$ profissão [online]. 2011, vol.31, n.2, pp. 268-283.

WALLERSTEIN, Judith; KELLY, Joan B. Sobrevivendo à Separação: como Pais e Filhos Lidam com o Divórcio. Porto Alegre: Artmed, 1998.

ZORZANELLI, Rafaela Teixeira; ORTEGA, Francisco; BEZERRA JUNIOR, Benilton. Um panorama sobre as variações em torno do conceito de medicalização entre 19502010. Ciênc. saúde coletiva, Rio de Janeiro, v. 19, n. 6, p. 1859-1868, Junho 2014. Disponível em <http://www.scielo.br/scielo.php?script=sci_arttext\&pid=S14131232014000601859\&lng=en\&nrm=iso >. Acesso em 04 Ago. 2020. https://doi.org/10.1590/1413-81232014196.03612013.

Débora Augusto Franco Instituto Federal de Educação, Ciência e Tecnologia do Rio de Janeiro, campus Pinheiral E-mail: debora.franco@ifrj.edu.br 